\title{
Quantitative analysis of changes in endometrial gland morphology during the bovine oestrous cycle and their association with progesterone levels
}

\author{
C K Wang, R S Robinson, A P F Flint and G E Mann \\ Division of Animal Physiology, School of Biosciences, University of Nottingham, Sutton Bonington Campus, \\ Loughborough LE12 5RD, UK \\ Correspondence should be addressed to G E Mann; Email: george.mann@nottingham.ac.uk
}

\begin{abstract}
This study describes a digital technique for uterine morphometry and its application to endometrial structure during the bovine oestrous cycle. Neither the number nor the size of uterine gland ducts changed during the cycle but a reduction in total endometrial area from days 0 to 8 after oestrus led to an increase in the proportion of the endometrium occupied by gland ducts (gland duct density). This effect on day 8 was maintained to day 16 . When endometrial morphology was related to circulating progesterone concentrations on days 5 and 8 of the luteal phase, no relationships were found on day 5, but on day 8, a high progesterone concentration was associated with an increased number of gland ducts. Furthermore, in animals slaughtered on day 8, a high progesterone concentration on day 5 was associated with decreased gland duct size, though a simultaneous decrease in endometrial area led to an increase in gland duct density. The results suggest that contrary to expectation, endometrial glands do not grow and regress during the oestrous cycle, although cyclic changes in endometrial area controlled by progesterone lead to changes in gland duct density.

Reproduction (2007) 134 365-371
\end{abstract}

\section{Introduction}

Morphometry has been successfully used to monitor pathological changes in the bovine endometrium (Gonzalez et al. 1985) and to study the effects of drugs and hormones on human endometrium (Johannisson et al. 1991). Recent developments in morphometrics have made the quantification of cyclic changes in endometrium feasible, and using these methods, it has been possible to identify the morphological changes occurring during the follicular and luteal phases in the human and ruminant uterus (Wahab et al. 1999, Dhaliwal et al. 2002). Furthermore, in human endometrium, glandular diameter during the proliferative and secretory phases has been correlated with oestrogen and progesterone levels (Johannisson et al. 1987). More recently in ruminants, morphometry has also been applied to the analysis of gland morphogenesis in animals depleted of uterine glands (Gray et al. 2001, Carpenter et al. 2003).

Changes in the cellular morphology of the bovine endometrium occurring during the oestrous cycle and in early pregnancy have been recorded in detail (Stinson et al. 1962, Marinov \& Lovell 1968, Kojima \& Selander 1970, Guillomot \& Guay 1982). Broadly, these changes reflect those observed in other species. There is an increase in the frequency of mitoses in the epithelium and stroma during the proliferative phase, when the epithelial cells become increasingly ciliated, and an increase in the branching of endometrial glands. This branching reaches a peak with the cessation of cell proliferation during the early secretory phase, when the basal cytoplasm of glandular epithelial cells becomes vacuolated with accumulating secretory material. Later, in the secretory phase, this material appears in the apical cytoplasm and fills the lumen of the glands. Despite an extensive knowledge of these changes, there is no automated technique for measurement of fluctuations in mean endometrial gland dimensions in whole uterine sections. Estimation of gland perimeter and area using digital imaging and image analysis software would represent an advance in terms of speed and accuracy (Wahab et al. 1999, Dhaliwal et al. 2002). The purpose of the present work was to provide such a technique and to use it to investigate the hormonal control of endometrial gland size.

An essential aspect of morphometric studies on endometrial glands is the selection of appropriate 
parameters for measurement and estimation. Possible parameters include number, diameter and the area occupied by glands. However, while measurement of the number and characteristics of gland ducts is possible, it is not practical to quantify the size of individual glands as there is no way of determining which ducts are associated with which glands. Since numbers of gland ducts in whole endometrial cross sections can be determined by eye, without the assistance by digital image analysis techniques, changes in endometrial gland number are most frequently determined directly by counting. However, failure to assess the size of gland ducts may result in an error in estimating gland function and lead to inaccuracies in the assessment of relatively small changes in endometrial glands, for example, during the oestrous cycle. Furthermore, secretory function is presumed to depend on the number of glandular epithelial cells in each gland. Therefore, when compared with other parameters, the perimeter of each gland may serve as a more appropriate parameter to use when estimating morphological changes of glands during the oestrous cycle. The aims of the present study were to develop a digital method for the analysis of endometrial structure, to assess the perimeter of the gland as a novel parameter for morphometric evaluation of changes in endometrial gland structure, to clarify morphological changes in endometrial glands during the oestrous cycle and to investigate their association with circulating progesterone levels.

\section{Materials and Methods \\ Experimental animals}

All studies were carried out in lactating multiparous Holstein/Friesian cows obtained from the University of Nottingham commercial dairy herd at the end of lactation. Oestrous cycles were synchronised by two injections of cloprostenol (estrumate; Schering-Plough Animal Health, Welwyn Garden City, UK) administered 12 days apart and the day of oestrus (day 0 ) was detected by $3 \times$ daily observations. All procedures were conducted under the Animals (Scientific Procedures) Act 1986.

In study 1, uterine tissue was obtained from cows slaughtered a) on the morning that oestrus was observed, while still showing behavioural signs of oestrus (day 0; $n=4)$, b) during the mid-luteal phase (day $8 ; n=4$ ) and c) during the late luteal phase (day $16 ; n=4$ ). In study 2 , uterine tissue was obtained from cows slaughtered on day $5(n=9)$ and day $8(n=9)$ after oestrus (day 0$)$ and blood samples were collected on days 5 and 8 for progesterone analysis. Progesterone was measured in plasma samples by a direct RIA (Law et al. 1992). Assay sensitivity was $1 \mathrm{nmol} / \mathrm{l}$, and intra- and inter-assay coefficients of variation were 13.5 and $12.2 \%$ respectively.

\section{Preparation of histological sections}

Uterine horn cross sections were collected from the horn contralateral to the corpus luteum at a point $5 \mathrm{~cm}$ from the uterotubual junction and fixed in $10 \%(\mathrm{v} / \mathrm{v})$ formalin in PBS for $24 \mathrm{~h}$ followed by $70 \%(\mathrm{v} / \mathrm{v})$ industrial methylated spirit (IMS, Fisher, Leicestershire, UK). The contralateral horn was chosen, rather than the ipsilateral horn, in order to exclude possible local effects of ovarian hormones on endometrial structure. Tissue was dehydrated and embedded in $70 \%$ IMS for $2 \mathrm{~h}, 90 \%$ IMS for $2 \mathrm{~h}$ twice, $100 \%$ IMS for $2 \mathrm{~h}$ twice, toluene for $2 \mathrm{~h}$ twice and paraffin wax for $2 \mathrm{~h}$ twice in an automatic tissue

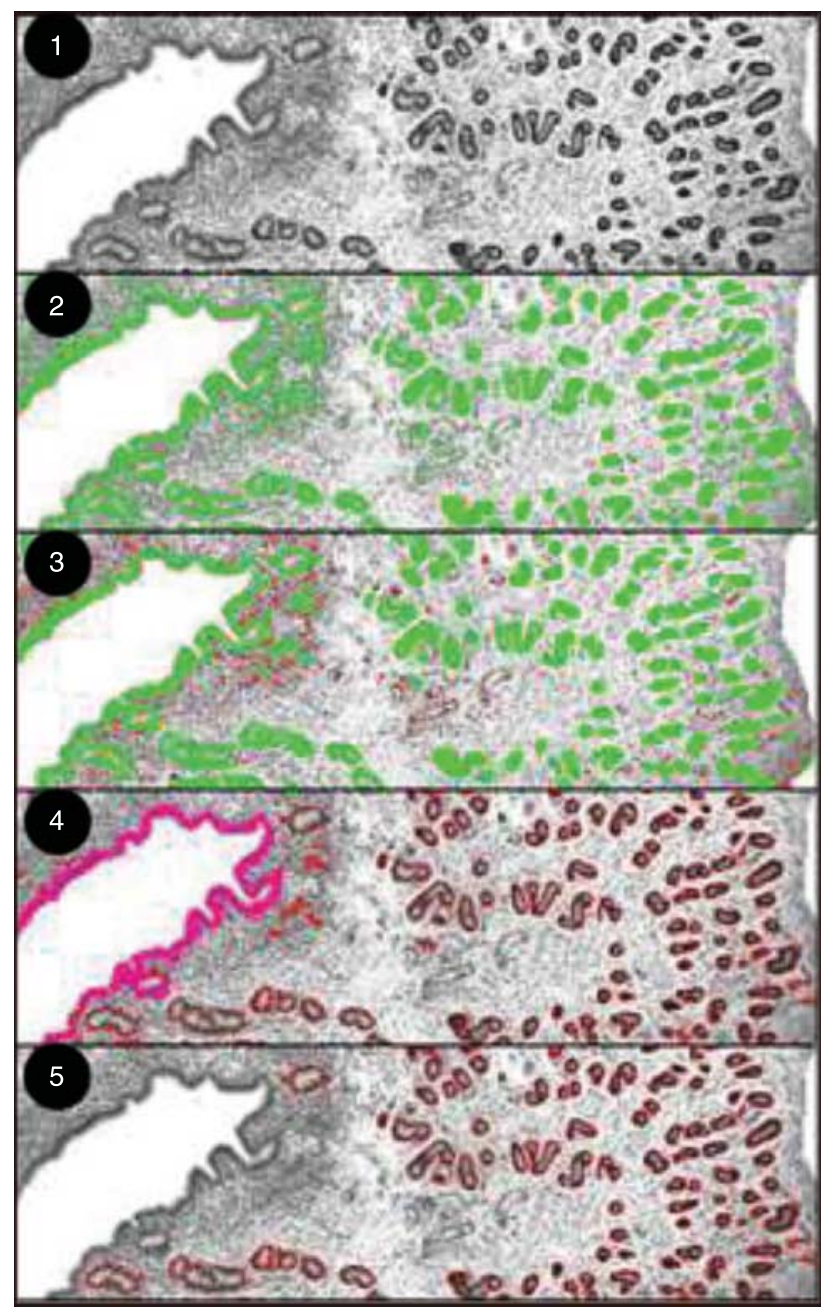

Figure 1 Use of SimplePCI software to quantify endometrial gland ducts in bovine endometrium. (1) A digital image of the endometrial section is uploaded; (2) threshold ranges of staining signal are set in order to automatically select the gland ducts, indicated in green; (3) threshold ranges are set to clean background noise, indicated in red, which is automatically deleted; (4) the selected gland duct staining is assessed and any inappropriate selections marked (indicated in magenta) and removed (in the figure, the luminal epithelium has been selected for deletion); (5) the corrected selected regions are then automatically analysed to determine parameters such as the number of selected gland ducts, the perimeter of gland ducts and the area of gland ducts. 


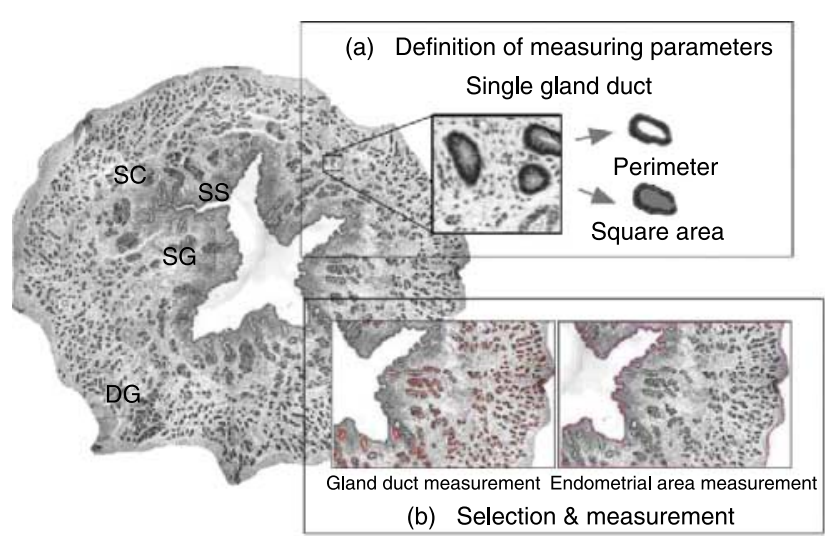

Figure 2 Processing of an image of a cross section of bovine uterus (a) Definition of gland ducts and parameters measured; (b) selection and measurement of total gland duct and total endometrial area. Measurements were performed automatically using SimplePCI software. SC, stratum compactum; SS, stratum spongiosum; DG, deep glands; SG, superficial or shallow glands.

processor (TP1020, Leica, Bucks Milton Keynes, UK). Embedded uterine horn tissue was sectioned at 6-8 $\mu \mathrm{m}$ using a microtome (HM355, Microm, Walldorf, Germany). Sections were stained by the haematoxylin and eosin method. They were rehydrated by washing in xylene for $5 \mathrm{~min}$ twice to remove excess paraffin followed by $100 \%$ IMS for 2 min twice, 95\% IMS for $1 \mathrm{~min}, 70 \%$ IMS for $1 \mathrm{~min}$ and running tap water for 2 min. Rehydrated sections were then stained in Harris's haematoxylin for $5 \mathrm{~min}$ and excess stain removed by washing under running tap water. After staining, sections were differentiated in $1 \%(\mathrm{v} / \mathrm{v})$ acetic acid/IMS for $2-4 \mathrm{~s}$ and washed in running tap water. The sections were then coloured blue with ammoniated water and transferred to $1 \%(\mathrm{v} / \mathrm{v})$ eosin/acetic acid solution for $5 \mathrm{~min}$ for eosin staining, before washing under running tap water again to remove excess eosin solution. Stains were then differentiated in $70 \%$ IMS for $2-4 \mathrm{~s}, 100 \%$ IMS for $1 \mathrm{~min}$ twice and xylene for 2 min twice. Sections were finally mounted in DPX (Raymond A LAMB, East Sussex, UK).

\section{Morphometric analyses}

Uterine endometrial sections stained with haematoxylin and eosin were photographed using a Leica DMR microscope with a Hamamatsu ORCA-ER C4742-95 digital camera (Hamamatsu, Hamamatsu city, Japan), which was controlled by SimplePCl software (Compix Inc., Cranberry Township, PA, USA). Captured digital image files were assembled and edited using Adobe Photoshop 5.0 (Adobe) and analysed by SimplePCI software as follows. After capture, digital image files were uploaded into the SimplePCl software. In the Identify Objects window, a threshold range of signal was selected to identify gland ducts and a threshold range was set to remove background noise. The selected noise signals were then deleted automatically and their deletion checked manually. Gland duct numbers, areas and perimeters were then estimated automatically in the Select Measurements window. To determine endometrial area, each endometrial section was selected manually and the area determined in the Select Measurements window. Outputs were then saved in SimplePCl as a data file. The procedure is described in Fig. 1.

When endometrial glands are transected histologically, a number of gland ducts are observed which may or may not represent the same gland. For this reason in this study, we refer to gland ducts rather than glands. For each uterine cross section, analysed endometrial gland ducts were counted and the perimeter $(\mu \mathrm{m})$ and area $\left(\mu \mathrm{m}^{2}\right)$ of individual gland ducts were measured (Fig. 2). Total endometrial area $\left(\mathrm{mm}^{2}\right)$ was also determined, allowing calculation of gland duct density (number of gland ducts per $\mathrm{mm}^{2}$ ) and percentage area of endometrium occupied by gland

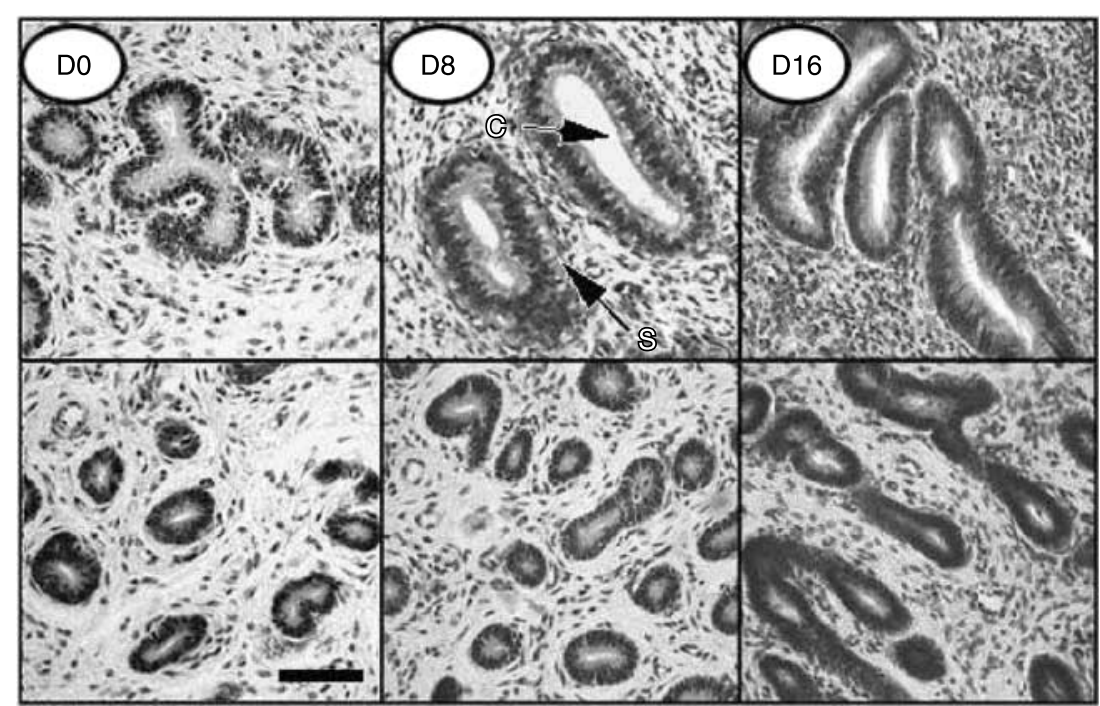

Figure 3 Sections of superficial and deep glands on day 0,8 and 16 of the oestrous cycle. Superficial glands in the stratum spongiosum are shown in the upper row and deep glands in the stratum compactum are in the lower row. C, ciliated epithelium cells and $\mathrm{S}$, the accumulation of secretory material. Scale bar $=100 \mu \mathrm{m}$. 
Table 1 Morphometric characteristics of endometrial glands in bovine endometrium during the oestrous cycle in study 1.

\begin{tabular}{|c|c|c|c|}
\hline \multirow[b]{2}{*}{ Parameters } & \multirow{2}{*}{$\begin{array}{c}\text { Follicular phase } \\
\text { Day } 0\end{array}$} & \multicolumn{2}{|c|}{ Luteal phase } \\
\hline & & Day 8 & Day 16 \\
\hline Total number of gland ducts per uterine cross section & $1829 \pm 149$ & $1366 \pm 191$ & $1515 \pm 209$ \\
\hline Mean gland duct perimeter $(\mu \mathrm{m})$ & $279 \pm 19$ & $339 \pm 37$ & $300 \pm 42$ \\
\hline Mean gland duct area $\left(\mu \mathrm{m}^{2}\right)$ & $3056 \pm 318$ & $3638 \pm 619$ & $3400 \pm 682$ \\
\hline Total endometrial area $\left(\mathrm{mm}^{2}\right)$ & $72.1 \pm 5.8^{\dagger}$ & $35.7 \pm 2.5$ & $40.6 \pm 2.1$ \\
\hline Gland duct density (ducts/mm² endometrium) & $25.3 \pm 5.3^{*}$ & $39.9 \pm 8.6$ & $38.0 \pm 6.4$ \\
\hline Gland duct area (\% of total endometrial area) & $7.8 \pm 0.9^{\dagger}$ & $13.0 \pm 1.3$ & $12.0 \pm 1.8$ \\
\hline
\end{tabular}

${ }^{*} P<0.05 ;{ }^{\dagger} P<0.001$ when compared with the luteal phase; $n=4$ animals on each day.

ducts (\%). Total endometrial area described the whole uterine endometrium including stratum compactum and stratum spongiosum, but excluded the myometrium and uterine lumen.

\section{Statistical analyses}

All data are presented as means \pm s.E.M. In study 1, endometrial characteristics on days 0,8 and 16 were compared by one-way ANOVA. In study 2, differences between days 5 and 8 were analysed by unpaired Student's $t$-test. Relationships between progesterone concentrations and endometrial characteristics were analysed by linear regression analysis. All statistical tests were carried out using Genstat version 8 (Lawes Agricultural Trust; obtained through VSN International Ltd, Hemel Hempstead, UK).

\section{Results}

\section{Study 1}

At a cellular level, the histological characteristics of the endometrium changed qualitatively during the oestrous cycle in the manner expected based on previous reports (Fig. 3; see the Introduction for references). Secretory material accumulated in the basal cytoplasm of the epithelial cells between days 0 and 8 . Cilia were clearly evident on both superficial and deep gland surfaces on day 8 , and by day 16 , all glandular epithelial cells were columnar, ciliated and fully developed and stromal cells appeared at their most dense.

Application of the automated morphometric method described here showed that these changes were not accompanied by changes in gland duct perimeter or area between the three stages of the oestrous cycle (Table 1). Total number of gland ducts was also similar though total endometrial area was significantly higher in samples collected during the follicular phase $(P<0.001)$. Since number of gland ducts was unchanged, while endometrial area increased, both gland duct density $(P<0.05)$ and total area occupied by gland ducts $(P<0.001)$ were lower in the follicular phase than at other stages of the cycle.

\section{Study 2}

Mean circulating progesterone levels on days 5 and 8 were $8.5 \pm 0.81$ and $18.6 \pm 1.85 \mathrm{nmol} / \mathrm{l}$ respectively $(P<0.01)$. There were no differences between days 5 and 8 in total endometrial area, average gland duct size (perimeter or area) or gland duct density per $\mathrm{mm}^{2}$ endometrium (Table 2). However, there was a trend towards a higher gland duct density (number per $\mathrm{mm}^{2}$ endometrium) on day $8(P<0.2)$.

On day 5 , there were no associations between plasma progesterone concentration and any of the morphometric parameters measured (Table 3). On day 8, total gland duct number increased with increasing progesterone concentration $(R=0.71 ; P<0.05)$ though no other parameters were associated with progesterone concentration at the time of slaughter. In the animals slaughtered on day 8 , a high day 5 progesterone concentration was associated with decreased total endometrial area and gland duct perimeter and area and with increased gland duct density (Table 3). Representative endometrial cross sections on day 8 from animals with high or low progesterone levels on day 5 (Fig. 4) reflect this relationship, and show that the association with progesterone level was particularly marked in deep glands. There were no significant correlations between endometrial morphology and the change in progesterone level between days 5 and 8 .

Table 2 Plasma hormone concentrations and morphometric characteristics endometrium in study 2 in animals killed on day $5(n=9)$ and day $8(n=9)$ of the luteal phase.

\begin{tabular}{lcc}
\hline Parameters & Day 5 & Day 8 \\
\hline $\begin{array}{l}\text { Plasma progesterone on day } \\
5(\mathrm{nmol} / \mathrm{l})\end{array}$ & $9.43 \pm 0.92$ & $7.48 \pm 0.70$ \\
$\begin{array}{l}\text { Plasma progesterone on day } \\
8(\mathrm{nmol} / \mathrm{l})\end{array}$ & - & $18.63 \pm 1.85$ \\
$\begin{array}{l}\text { Total number of gland ducts per } \\
\text { uterine cross section }\end{array}$ & $1202 \pm 171$ & $1313 \pm 151$ \\
$\begin{array}{l}\text { Mean gland duct perimeter }(\mu \mathrm{m}) \\
\text { Mean gland duct area }\left(\mu \mathrm{m}^{2}\right)\end{array}$ & $358 \pm 29$ & $315 \pm 19$ \\
$\begin{array}{l}\text { Total endometrial area }\left(\mathrm{mm}^{2}\right) \\
\text { Gland duct density }\left(\text { ducts } / \mathrm{mm}^{2}\right.\end{array}$ & $3961 \pm 454$ & $3457 \pm 339$ \\
$\begin{array}{l}\text { endometrium) } \\
\text { Gland duct area }(\% \text { of total }\end{array}$ & $33.7 \pm 3.4$ & $31.4 \pm 2.9$ \\
endometrial area) & $12.5 \pm 1.1$ & $13.3 \pm 4.5$ \\
\hline
\end{tabular}


Table 3 Correlation coefficients between progesterone concentrations on day 5 and 8 and morphometric parameters.

\begin{tabular}{|c|c|c|c|}
\hline & \multirow{2}{*}{$\begin{array}{c}\text { Day } \mathbf{5} \\
\text { Correlations with day } 5 \\
\text { progesterone }\end{array}$} & \multicolumn{2}{|c|}{ Day 8} \\
\hline & & $\begin{array}{l}\text { Correlations with day } 5 \\
\text { progesterone }\end{array}$ & $\begin{array}{c}\text { Correlations with day } 8 \\
\text { progesterone }\end{array}$ \\
\hline Total number of gland ducts per uterine cross section & 0.05 & 0.12 & $0.71 *$ \\
\hline Mean gland duct perimeter $(\mu \mathrm{m})$ & 0.15 & $-0.76^{*}$ & -0.46 \\
\hline Mean gland duct area $\left(\mu \mathrm{m}^{2}\right)$ & 0.16 & $-0.68^{*}$ & -0.33 \\
\hline Total endometrial area $\left(\mathrm{mm}^{2}\right)$ & -0.34 & $-0.70^{*}$ & 0.21 \\
\hline Gland duct density (ducts $/ \mathrm{mm}^{2}$ endometrium) & 0.22 & $0.67^{*}$ & 0.45 \\
\hline Gland duct area (\% of total endometrial area) & 0.10 & 0.35 & 0.45 \\
\hline
\end{tabular}

For animals slaughtered on day 8 , both day 8 and day 5 progesterone concentrations are available $(* P<0.05)$.

\section{Discussion}

When assessing endometrial morphology, gland duct number has most frequently been used to quantify changes for diagnostic purposes or following clinical treatments in both humans and farm animals (Gonzalez et al. 1985, Johannisson et al. 1987, Wahab et al. 1999, Gray et al. 2001, Carpenter et al. 2003). However, some authors have reported that numbers of endometrial glands do not change during the natural cycle (Johannisson et al. 1987, 1991, Wahab et al. 1999).

Other morphological parameters including glandular area, diameter and volume have been used to evaluate changes in the structure and function of endometrial glands more accurately. Wahab et al. (1999) reported that gland area and diameter differ between the follicular and luteal phases in the human endometrium. In cattle, Dhaliwal et al. (2002) used two-dimensional and threedimensional analyses to evaluate endometrial gland changes between the follicular and luteal phases. In heifers, a number of parameters differed between the follicular and luteal phase, while in cows, gland area was the only parameter that differed. However, as endometrial gland secretion is a function of epithelial cells lining the lumen of glands, the perimeter of an individual duct rather than its cross-sectional area may be more closely associated with a gland's secretory capacity.

In the present study, the total number of endometrial gland ducts was similar in the follicular and luteal phases. Furthermore, neither the perimeter nor area of individual gland ducts changed between the follicular and luteal phases. Since total endometrial area was greater during the follicular phase, the density of gland ducts (number per $\mathrm{mm}^{2}$ ) was reduced. The decrease in endometrial area during the transition from the follicular to the luteal phase presumably reflected a reduction in the oedema associated with oestrus. This is inconsistent

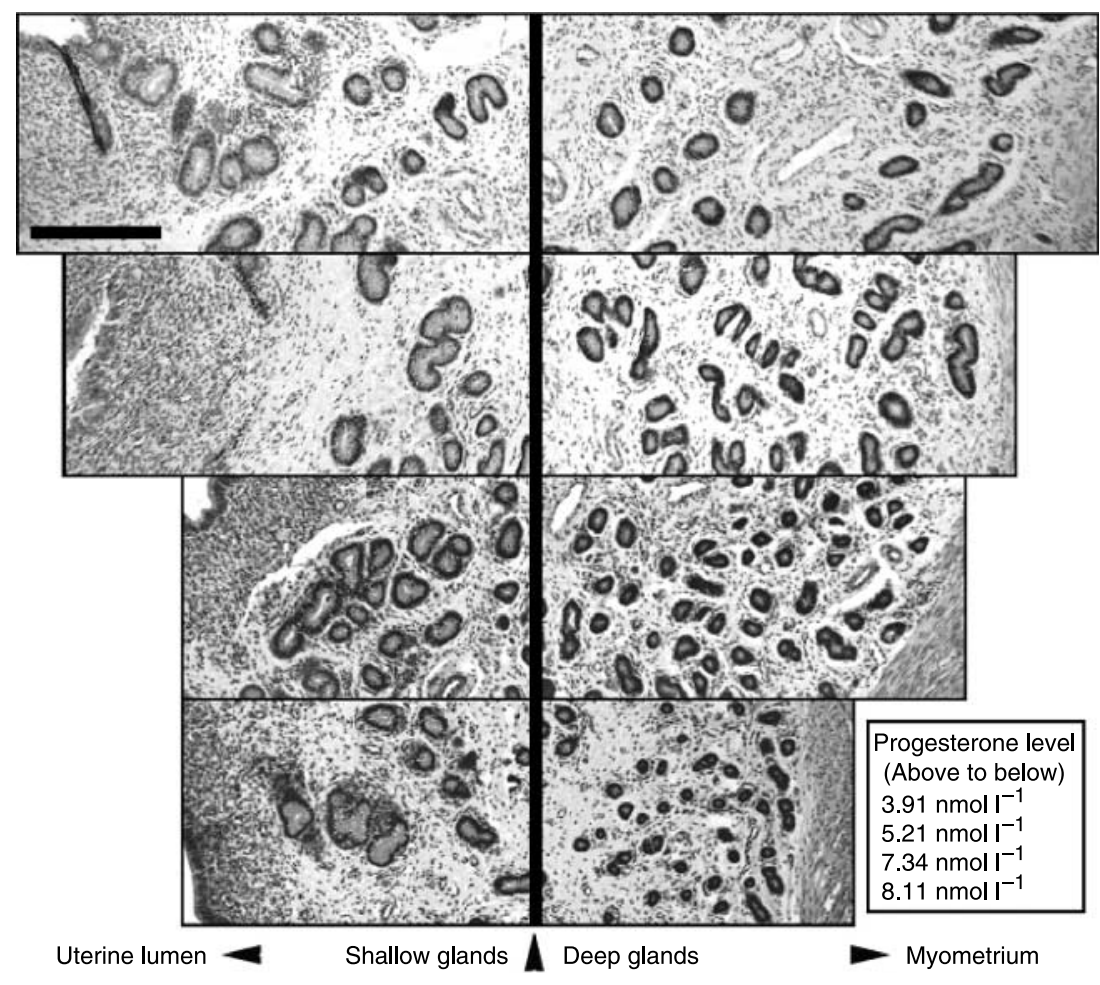

Figure 4 Endometrial samples obtained on day 8 from cows with high or low progesterone levels on day 5 . All four cross sections are to the same scale $($ bar $=250 \mu \mathrm{m})$. 
with the assumption that the endometrium proliferates to thicken at the secretory luteal phase (Roberts 1971).

Endometrial morphometry is widely used to quantify endometrial changes after hormone replacement treatment in women (Casanas-Roux et al. 1996, Habiba et al. 1998, Wahab et al. 1999). However, few investigations have been carried out on the relationship between steroid hormone levels and endometrial changes in the natural cycle, especially in ruminants. Though morphological changes in endometrial glands and stroma such as oedema and epithelial hyperplasia are considered to be controlled by steroid hormones, the relationship between cyclic endometrial changes and progesterone levels remains unclear. The present study clarifies several such relationships between plasma progesterone levels and endometrial changes during the secretory phase.

On day 8 , total endometrial area as well as endometrial gland perimeter and area were all negatively correlated with plasma progesterone concentration measured in the same animals on day 5. This indicates that a higher concentration of progesterone on day 5 is associated with a lower total endometrial area on day 8 and suggests that endometrial thickness and gland size during the early secretory phase may be regulated by the rate at which progesterone levels rise during formation of the corpus luteum. In contrast, gland duct density on day 8 was positively associated with progesterone level on day 5 . This response probably reflects the decrease in endometrial area in response to a high level of progesterone on day 5 , the same number of gland ducts occupying a reduced area. Interestingly, on day 8 , gland ducts in endometrium exposed to a high progesterone level on day 5 appeared to be smaller and more condensed in deep glands than in shallow ones, possibly also reflecting the reduction in endometrial area through compression by the regressing stroma. This observation, which may indicate that progesterone affects deep and shallow glands differentially, needs further investigation. Levels of progesterone receptor are low in both deep and shallow glands on day 16 (Robinson et al. 1999) and as far as we are aware there is no other evidence to suggest a differential sensitivity to progesterone. Together, these results suggest that endometrial gland morphology is associated with circulating progesterone concentrations during the early luteal phase.

The morphological changes observed in endometrial cells reflect the differentiation, proliferation and migration of different cell types during the proliferative and early secretory phases of the cycle (Gray et al. 2001). These cellular changes are controlled by steroid hormones, growth factors and the extracellular matrix (Ohtani et al. 1993, Johnson et al. 1997, Rider et al. 1998, Kimmins \& MacLaren 1999). The extracellular matrix is involved in cell-cell interactions during cell proliferation and migration (Juliano \& Haskill 1993, Gille \& Swerlick 1996) and therefore plays a key role in endometrial cellular regulation. In vivo and in vitro experiments have shown that some extracellular matrix factors such as integrin receptor $\alpha_{v} \beta_{3}$ are regulated by progesterone and oestradiol (Bowen et al. 1996, Castelbaum et al. 1997, Somkuti et al. 1997, Kimmins \& MacLaren 1999). Various growth factors that are regulated by gonadal steroid hormones, such as transforming growth factor- $\beta$, influence the expression of integrin $\alpha_{v} \beta_{3}$ in the endometrium (Ignotz et al. 1989, Yang et al. 1996, Somkuti et al. 1997, Flores et al. 1998). In some cases, these compounds are differentially expressed in various endometrial cell types (Kimmins \& MacLaren 1999), providing the opportunity for differential morphological changes, such as that suggested here in shallow and deep glands. The morphological changes in endometrial thickness and gland ducts may reflect interactions between gonadal steroid hormones, growth factors and extracellular matrix components in endometrial epithelial and stromal cells.

The cyclic changes in total endometrial area observed here show that cyclic changes in endometrial gland duct density may be driven by changes in total endometrial area rather than by the proliferation and regression of glandular epithelial cells. The morphometric method described can be used to detect endometrial changes during the early secretory phase that appear to be associated with progesterone concentration. This analytical method is therefore a potentially useful tool with which to evaluate endometrial gland function.

\section{Acknowledgement}

The authors declare that there is no conflict of interest that would prejudice the impartiality of this scientific work

\section{References}

Bowen JA, Bazer FW \& Burghardt RC 1996 Spatial and temporal analyses of ontegrin and Muc-1 expression in porcine uterine epithelium and trophectoderm in vivo. Biology of Reproduction $\mathbf{5 5}$ 1098-1106.

Carpenter KD, Gray CA, Noel S, Gertler A, Bazer FW \& Spencer TE 2003 Prolactin regulation of neonatal ovine uterine gland morphogenesis. Endocrinology 144 110-120.

Casanas-Roux F, Nisolle M, Marbaix E, Smets M, Bassil S \& Donnez J 1996 Morphometric, immunohistological and three-dimensional evaluation of the endometrium of menopausal women treated by oestrogen and crinone, a new slow-release vaginal progesterone. Human Reproduction 11 357-363.

Castelbaum AJ, Ying L, Somkuti SG, Sun J, Ilesanmi AO \& Lessey BA 1997 Characterization of integrin expression in a well differentiated endometrial adenocarcinoma cell line (Ishikawa). Journal of Clinical Endocrinology and Metabolism 82 136-142.

Dhaliwal GS, Murry RD, Rees EM, Howard CV \& Beech DJ 2002 Quantitative unbiased estimates of endometrial gland surface area and volume in cycling cows and heifers. Research in Veterinary Science 73 259-265. 
Flores JM, Sánchez MA, Garcia P \& Nieto A 1998 Immunohistochemical localization of epidermal growth factor, transforming growth factor- $\alpha$ and growth factor- $\beta \mathrm{s}$ in the caprine peri-implantation period. Theriogenology 50 931-944.

Gille J \& Swerlick RA 1996 Integrins: role in cell adhesion and communication. Annals of the New York Academy of Sciences 797 93-106.

Gonzalez HE, Crowell WA, Caudle AB \& Thompson FN 1985 Morphometric studies of the bovine uterus: miscroscopic lesions and retrospective reproductive history. American Journal of Veterinary Research 46 2588-2595.

Gray CA, Bazer FW \& Spencer TE 2001 Effects of neonatal progestin exposure on female reproductive tract structure and function in the adult ewe. Biology of Reproduction 64 797-804.

Guillomot M \& Guay P 1982 Ultrastructural features of the cell surfaces of uterine and trophoblastic epithelia during embryo attachment in the cow. Anatomical Record 204 315-322.

Habiba MA, Bell SC \& Al-Azzawi F 1998 Endometrial responses to hormone replacement therapy: histological features compared with those of late luteal phase endometrium. Human Reproduction 13 1674-1682.

Ignotz RA, Heion J \& Massagué J 1989 Regulation of cell adhesion receptors by transforming growth factor- $\beta$. Journal of Biological Chemistry 264 389-392.

Johannisson E, Landgren BM, Rohr HP \& Diczfalusy E 1987 Endometrial morphology and peripheral hormone levels in women with regular menstrual cycles. Fertility and Sterility 48 401-408.

Johannisson E, Brosens I, Cornillie F, Elder M, White J, Sheppard B, Horihan H, d'Arcangues C \& Belsey EM 1991 Morphometric study of the human endometrium following continuous exposure to levonorgestrel released from vaginal rings during 90 days. Contraception 43 361-371.

Johnson ML, Redmer DA \& Reynolds LP 1997 Effects of ovarian steroids on uterine growth, morphology, and cell proliferation in ovariectomized, steroid treated ewes. Biology of Reproduction 57 588-596.

Juliano RL \& Haskill S 1993 Signal transduction from the extracellular matrix. Journal of Cell Biology 120 577-585.

Kimmins S \& MacLaren LA 1999 Cyclic modulation of integrin expression in bovine endometrium. Biology of Reproduction $\mathbf{6 1}$ $1267-1274$

Kojima Y \& Selander U 1970 Cyclical changes in the fine structure of bovine endometrial gland cells. Zeitschrift fur Zellforschung und Mikroskopische Anatomie 104 69-86.

Law AS, Baxter G, Logue DN, O'Shea T \& Webb R 1992 Evidence for the action of bovine follicular fluid factor(s) other than inhibin in suppressing follicular development and delaying estrus in heifers. Journal of Reproduction and Fertility $\mathbf{9 6}$ 603-616.

Marinov U \& Lovell JE 1968 Cytology of the bovine uterine epithelium during the estrous cycle. American Journal of Veterinary Research $\mathbf{2 9}$ 13-30.

Ohtani S, Okuda K, Nishimura K \& Mohro S 1993 Histological changes in bovine endometrium during the estrous cycle. Theriogenology 39 1033-1042.

Rider V, Kimler BD \& Justice WM 1998 Progesterone-growth factor interactions in uterine stromal cells. Biology of Reproduction $\mathbf{5 9}$ 464-469.

Roberts SJ 1971 Physiology of female reproduction. In Veterinary Obstetrics and Genital Diseases (Theriogenology), edn 2, pp 343375. New York: Raven Press.

Robinson RS, Mann GE, Lamming GE \& Wathes DC 1999 The effect of pregnancy on the expression of uterine oxytocin, oestrogen and progesterone receptors during early pregnancy in the cow. Journal of Endocrinology 160 21-33.

Somkuti SG, Yuan L, Fritz MA \& Lesse BA 1997 Epidermal growth factor and sex steroids dynamically regulate a marker of endometrial receptivity in Ishikawa cells. Journal of Clinical Endocrinology and Metabolism 82 2192-2197.

Stinson AW, Weber AF \& Jemjanis R 1962 The bovine endometrium an Electron Microscopic Study. American Journal of Veterinary Research 23 1164-1182.

Wahab M, Thompson J, Hamid B, Deen S \& Al-Azzawi F 1999 Endometrial histomorphometry of trimegestone-based sequential hormone replacement therapy: a weighted comparison with the endometrium of the natural cycle. Human Reproduction 14 2609-2618.

Yang NN, Bryant HU, Hardikar S, Sato M, Galvin RJS, Glasebrook AL \& Termine JD 1996 Estrogen and raloxifene stimulate transforming growth- $\beta 3$ gene expression in rat bone: a potential mechanism for estrogen- or raloxifene-mediated bone maintenance. Endocrinology 137 2075-2084.

Received 4 August 2006

First decision 1 September 2006

Revised manuscript received 12 April 2007

Accepted 20 April 2007 